\section{Influence of the Resin Cement Thickness on the Push-Out Bond Strength of Glass Fiber Posts}

Regina Maria Helen-Cot Marcos, Gustavo Ross Kinder, Edson Alfredo, Tarcisio Quaranta, Gisele Maria Correr, Leonardo Fernandes da Cunha, Carla Castiglia Gonzaga
Graduate Program in Dentistry, UP - Universidade Positivo, Curitiba, PR, Brazil

Correspondence: Carla Castiglia Gonzaga, Rua Prof. Pedro Viriato Parigot de Souza, 5300, 81280330 Curitiba, PR, Brasil. Tel: +55-41-3317-3180. e-mail: carlacgonzaga2@gmail.com
The objective of the present study was to evaluate the influence of resin cement thickness on the bond strength of prefabricated and customized glass fiber posts after storage in distilled water. Thirty human uniradicular roots were treated endodontically. The roots were divided into 3 groups: THIN (thin cement layer) - post space preparation with \#0.5 drill and cementation of \#0.5 post; THICK (thick cement layer) - post space preparation with \# 1 drill and cementation of \#0.5 post; and CUSTOM (customized cement layer) post space preparation with \#1 drill and cementation of a customized post (\#0.5 glass fiber posts customized with resin composite). All posts were luted with self-adhesive resin cement. The push-out test was carried out after storage for $24 \mathrm{~h}$ and 90 days in distilled water at $37^{\circ} \mathrm{C}$. The data were analyzed with three-way ANOVA and Tukey's test ( $\left.\alpha=0.05\right)$. Bond strengths were significantly higher for CUSTOM (9.37 MPa), than for THIN (7.85 MPa) and THICK (7.07 MPa), which were statistically similar. Considering the thirds, the bond strength varied in the sequence: apical $(7.13 \mathrm{MPa})<$ middle $(8.22 \mathrm{MPa})=$ coronal $(8.94$ $\mathrm{MPa})$. Bond strength for $24 \mathrm{~h}$ storage was significantly higher ( $8.80 \mathrm{MPa})$ than for 90 -day storage (7.40 MPa). It may be concluded that the thickness of resin cement influenced the bond strength of glass fiber posts. The customized posts presented higher bond strength. Storage in water for 90 days affected negatively the values of bond strength, especially for thick cement layers in the apical third.
Key Words: cement thickness, glass fiber posts, bond strength.

\section{Introduction}

Restoration of teeth with little remaining coronal structure commonly calls for cast metal posts to provide the required retention for the prosthetic crown. However, they exhibit some unfavorable characteristics, such as the possibility of oxidation and corrosion, irregular dissipation of masticatory forces, stress concentration in the apical region, which may lead to unfavorable root fracture (1).

Prefabricated glass fiber posts, adhesively cemented to the root dentin, have been increasingly used for restoring endodontically treated teeth in order to compensate the disadvantages of the metal cast posts. Because the elastic modulus of the glass fiber posts (10 to $25 \mathrm{GPa}$ ) (2) is close to that of dentin, there is a better distribution of stresses. In addition, these aesthetic posts are more practical, less expensive and less invasive than cast metal posts and cores. Prefabricated glass fiber posts are indicated when there is at least $2 \mathrm{~mm}$ of coronal structure, but because of their standardized forms, these prefabricated posts cannot be adapted to all cross-sectional shapes of root canals.

In many cases, drills with the same diameter of the prefabricated glass fiber posts allow a good fit of the posts into the root canals, but there are situations in which the canals can have different shapes (3), causing variations in the resin cement layer thickness (4). Therefore, in cases where the post does not adapt well to the root canal walls, especially in the coronal third, the resin cement layer will tend to be thick and present bubbles and voids, two factors that predispose to failure $(5,6)$. Other clinical conditions that may compromise the adaptation of the post to the root canal walls are flattened canals, trauma, pulp disease and iatrogenics (7). In these cases have been proposed the customized glass fiber posts (8-10), since they exhibit thinner and more uniform resin cement layers, particularly in the coronal and middle thirds (5).

Literature has reported conflicting results about the influence of the resin cement thickness on the bond strength of prefabricated and customized glass fiber posts. Some studies have suggested that a thick layer of cement may stimulate the displacement of glass fiber posts $(7,11-13)$, but other studies $(14,15)$ showed that the bond strength was not influenced by the increased thickness of the resin cement film.

The long-term failure rate of glass fiber posts ranges from 7 to $11 \%$ (16). In addition to the endodontic problems, the main cause of failure has been the post debonding by adhesive failure at the post/resin cement or resin cement/ 
dentin interfaces (16). Thus, an intimate contact of all substrates involved in the adhesive interfaces may be critical for a better bond and this may improve the clinical success of the restoration of endodontically treated teeth.

The objective of this study was to evaluate the influence of resin cement thickness on the push-out bond strength of prefabricated and customized glass fiber posts to dentin, after storage in distilled water for $24 \mathrm{~h}$ and 90 days. The null hypotheses were: i) there would be no influence of the resin cement thickness on the bond strength of customized and prefabricated glass fiber posts, and ii) after storage in water for 90 days, there would be no decrease in the bond strength values, regardless the resin cement thickness.

\section{Material and Methods}

Thirty recently extracted human uniradicular teeth (maxillary incisors, canines and premolars) were collected, cleaned and immersed in chloramine T $0.5 \%$ at $4{ }^{\circ} \mathrm{C}$ until use. For the study purposes, they had to be single-rooted teeth with fully developed root apex, free of decay, fractures or root anomalies and without endodontic treatment.

The teeth had their crowns removed to create a standard access to the root canal and root portions at least $14 \mathrm{~mm}$ long. The same operator performed the root canal preparations with rotatory ProTaper universal files (Dentsply Maillefer, Ballaigues, Switzerland). The irrigating solutions were $2.5 \% \mathrm{NaOCl}$ and $17 \%$ EDTA. After the final irrigation, the canals were dried with paper points (Roeko paper points; Coltene/Whaledent, Cuyahoga Falls, Ohio, USA) and filled with gutta-percha and AHPlus (Dentsply Maillefer) using the Tagger's hybrid technique.

After $24 \mathrm{~h}$, the post spaces were prepared at a $10 \mathrm{~mm}$ depth from the cemento-enamel junction, maintaining a 4 $\mathrm{mm}$ apical seal. The diameter of the post space preparations was standardized by the diameter of the drill used in each group. The post spaces were irrigated with distilled water and dried with paper points. The specimens were randomly divided into three groups for the cementation of prefabricated and customized glass fiber post, according to the resin cement thickness:

THIN (thin cement layer): post spaces were prepared with a drill corresponding to the \#0.5 post, $\emptyset 1.4 \mathrm{~mm}$ coronal and apical $\emptyset 0.65 \mathrm{~mm}$, (DC White Post; FGM, Joinville, SC, Brazil), and a pre-fabricated \#0.5 glass fiber post was luted (FGM);

THICK (thick cement layer): post spaces were prepared with a drill corresponding to the \#1 post, $\varnothing 1.6 \mathrm{~mm}$ coronal and apical $\emptyset 0.85 \mathrm{~mm}$ (FGM), and a pre-fabricated \#0.5 glass fiber post was luted (FGM);

CUSTOM (custom cement layer): post spaces were prepared with a drill corresponding to the \#1 post, $\varnothing 1.6$ $\mathrm{mm}$ coronal and apical $\emptyset 0.85 \mathrm{~mm}$ (FGM), and a customized glass fiber post was luted.

The customized posts were fabricated using \# 0.5 glass fiber posts (FGM) covered with a layer of composite resin. The post spaces were cleaned and isolated with a thin layer of glycerol. The glass fiber posts were etched with 37\% phosphoric acid (Condac 37; FGM) for $15 \mathrm{~s}$, washed thoroughly with water and dried. A layer of adhesive (Ambar; FGM) was applied, followed by a light air jet, light curing for $15 \mathrm{~s}$ and the increments of composite resin (Glacier; SDI, Victoria, Australia) were added to the posts. The posts were inserted into the isolated post spaces for modeling and then removed. The composite resin was light-cured for $40 \mathrm{~s}$. A LED curing light (Poly Wireless; Kavo, Joinville, SC, Brazil), with $1100 \mathrm{~mW} / \mathrm{cm}^{2}$ irradiance was used throughout the experiment. Copious rinsing was used to remove the glycerol from the post spaces.

Prior to cementing, both posts, prefabricated and customized, were cleaned with 37\% phosphoric acid for $15 \mathrm{~s}$ (Condac 37; FGM), washed and dried. A layer of silane coupling agent (Prosil; FGM) was applied with a microbrush for $60 \mathrm{~s}$.

The posts were luted with self-adhesive resin cement (SeT; SDI) with manual pressure. The excess was immediately removed and the cement was light-cured for $40 \mathrm{~s}$. Next, the specimens were stored in distilled water at $37{ }^{\circ} \mathrm{C}$ for $24 \mathrm{~h}$ and 90 days before the push-out test.

The roots were placed in PVC tubes and embedded in acrylic resin (Duralay; Reliance Dental, Alsip, IL, USA). The part of each root that contained the bonded fiber post was sectioned perpendicular to the long axis into six 1-mmthick slices. A diamond cutting saw (Isomet 1000; Buehler, Lake Bluff, IL, USA) was used under water cooling to create two cervical, two middle and two apical slices.

The coronal side of each slice was identified and its thickness was measured with a digital caliper (799; Starrett, Itu, SP, Brazil) with $0.01 \mathrm{~mm}$ accuracy. Each slice was subjected to push-out bond strength test in a universal testing machine (EMIC DL 2000; Emic, São José dos Pinhais, PR, Brazil) at a crosshead speed of $0.5 \mathrm{~mm} / \mathrm{min}$. The load was applied in the apical-coronal direction until the dislodgment of the post. For all tests, the push-out pin at the center of the post surface was carefully placed and different sizes of punch pins were used to match the diameter of the post at the different tested root thirds.

The maximum failure load was recorded in Newton $(\mathrm{N})$ and converted into MPa by dividing the applied load by the bonded area. The bonded area is the lateral area of a truncated cone, which was calculated bv the formula:

$$
A=\pi(R+r) \sqrt{h^{2}+(R-r)^{2}}
$$

where $A$ is the lateral area of a truncated cone, $\pi=3.14$, 
$\mathrm{R}=$ coronal post radius, $\mathrm{r}=$ apical post radius and $\mathrm{h}=$ root slice thickness.

Failure modes of all specimens were evaluated under a stereomicroscope with 57× magnification (SZX9; Olympus, Tokyo, Japan) and classified as: adhesive failure between dentin and resin cement; adhesive failure between resin cement and post; adhesive failure between resin composite and post; cohesive failure within resin cement; cohesive failure within the post; cohesive failure within dentin and mixed failure.

Data were statistically analyzed using three-way ANOVA (groups, root thirds and storage time) and Tukey's test with a 0.05 significance level. Correlation between resin cement thickness and bond strength values was made by the coefficient of determination $\left(R^{2}\right)$.

\section{Results}

The means and standard deviations of the bond strength, according to the tested groups, root thirds and storage times are in Table 1.

The results showed statistically significant differences for the triple interaction group*third*time $(p=0.012)$ and all individual factors: groups $(p<0.0001)$, root thirds $(p<0.0001)$ and storage time $(p<0.0001)$. There was no statistically significant difference for all double interactions.

Among the groups, CUSTOM $(9.37 \pm 0.24 \mathrm{MPa})$ showed higher bond strength values compared to the THIN and THICK groups, which were statistically similar $(7.85 \pm 0.24$ $\mathrm{MPa}$ and $7.07 \pm 0.24 \mathrm{MPa}$, respectively). For the root thirds, the bond strength was higher for coronal and middle thirds $(8.94 \pm 0.24 \mathrm{MPa}$ and $8.22 \pm 0.24 \mathrm{MPa}$, respectively), which were statistically similar, and lower for the apical third $(7.13 \pm 0.24 \mathrm{MPa})$. As to the storage time, the bond strength values were higher for the 24-h storage time than for the 90 -day storage $(8.80 \pm 0.19 \mathrm{MPa}$ to $7.41 \pm 0.19$

Table 1. Means and standard deviations for bond strength according to the group, root third and storage time

\begin{tabular}{lccc}
\hline \multirow{2}{*}{ Group } & Root third & \multicolumn{2}{c}{ Bond strength (MPa) } \\
\cline { 3 - 4 } & & $24 \mathrm{~h}$ & 90 days \\
\hline \multirow{3}{*}{ THIN } & Coronal & $9.07 \pm 2.64 \mathrm{abc}$ & $7.71 \pm 2.42^{\mathrm{abcd}}$ \\
& Middle & $8.59 \pm 2.29 \mathrm{abc}$ & $8.35 \pm 2.43^{\mathrm{abc}}$ \\
& Apical & $7.99 \pm 2.16^{\mathrm{abcd}}$ & $5.36 \pm 0.90 \mathrm{de}$ \\
\multirow{2}{*}{ THICK } & Coronal & $8.47 \pm 2.47 \mathrm{abc}$ & $7.93 \pm 2.39 \mathrm{abcd}$ \\
& Middle & $7.77 \pm 1.72^{\mathrm{abcd}}$ & $6.15 \pm 1.56^{\mathrm{cde}}$ \\
& Apical & $8.29 \pm 1.89 \mathrm{abc}$ & $3.84 \pm 0.96 \mathrm{e}$ \\
\multirow{2}{*}{ CUSTOM } & Coronal & $10.63 \pm 3.09 \mathrm{a}$ & $9.72 \pm 3.03 \mathrm{ab}$ \\
& Middle & $9.71 \pm 2.74 \mathrm{ab}$ & $8.44 \pm 2.08 \mathrm{abc}$ \\
& Apical & $8.59 \pm 1.59 \mathrm{abc}$ & $8.70 \pm 1.85^{\mathrm{abc}}$ \\
\hline
\end{tabular}

Values followed by the same letter are statistically similar ( $>0.05)$.
$\mathrm{MPa}$, respectively).

For both storage times, a strong negative correlation was observed between the resin cement thickness and the bond strength values (Fig. 1), indicating that the greater the resin cement thickness, the lower the bond strength values ( $R^{2}$ correlation coefficient of 0.92582 and 0.98323 for 24-h and 90-day of storage, respectively). The dashed line indicates the correlation considering both times with an $R^{2}$ correlation coefficient of 0.96845 . The coefficient of determination $\left(R^{2}\right)$ is a statistical measure of how close the data are to the line of best fit (described by the regression equation).

Figure 2 shows the failure modes after the push-out test. For all groups, the failures were predominantly adhesive between resin cement and post, adhesive between resin cement and dentin and, in a few cases, mixed. None of the specimens showed cohesive failure.

Representative images of the coronal slices of all three groups are in Figure 3. A good adaptation of the glass fiber post to the prepared post space with a thin cement layer is presented in Figure $3 \mathrm{~A}$; a thick resin cement film can be observed in Figure $3 \mathrm{~B}$; and Figure $3 \mathrm{C}$ shows a customized post with a layer of translucent composite resin, well adapted to the prepared post space, with no visible resin cement layer .

\section{Discussion}

As there was no influence of the resin cement thickness on the bond strength of prefabricated and custom glass fiber posts, the first hypothesis was rejected. Customized glass fiber posts showed higher bond strength values than the prefabricated posts. Considering only the prefabricated posts, with thick and thin cement layers, there was no statistically significant difference between the groups. However, it should be clear that this study used a customized glass fiber post as an attempt to further reduce the thickness of resin cement, obtaining a post that would fit over the

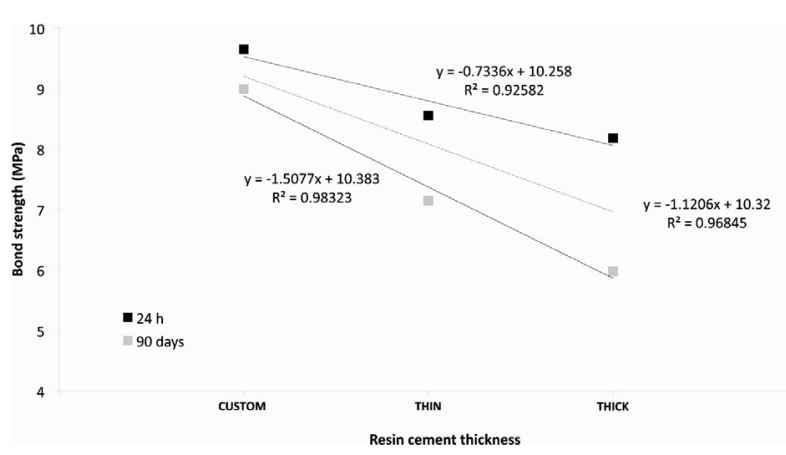

Figure 1. Correlation plot between resin cement thickness and bond strength. The dashed line indicates the correlation considering both storage times. 
prepared post space along its entire length.

Grandini et al. (5) suggested that if a post is not well fitted to the root canal, especially in the coronal third, the resulting cement layer is thick and susceptible to air bubbles and voids, which would increase the chances of failure and displacement of the post. Formation of these bubbles would be less probable in thinner and more uniform cement films. Furthermore, the polymerization stresses developed in relatively thin cement layers would be minimal. Thus, customized posts, which have a good adaptation to the prepared post spaces, may have a higher retention, a hypothesis that should be confirmed in further clinical studies.

In the present study, the group of customized posts showed higher bond strength values, which may be attributed to the presence of a thin and uniform resin cement layer. So, because of their form after modeling with composite resin, they are better adapted to the post spaces, increasing the retention.

In this work, customization of the glass fiber posts was made with composite resin $(10,17)$. The literature also reports other techniques for post customization and reducing the thickness of cement layer, like for example, the use of unidirectional glass fibers (8) and zirconia posts made with CAD-CAM technology (9). The customization technique with composite resin was chosen because it has some advantages, such as: use of readily available materials in the dental office, less clinical time, ease of use, no need for using sophisticated equipment, as CAD-CAM and no requirement to take impressions. However, some disadvantages should be mentioned, as the addition of a bonding interface between the fiber post and the composite resin, which may be subject to failure. It should also be

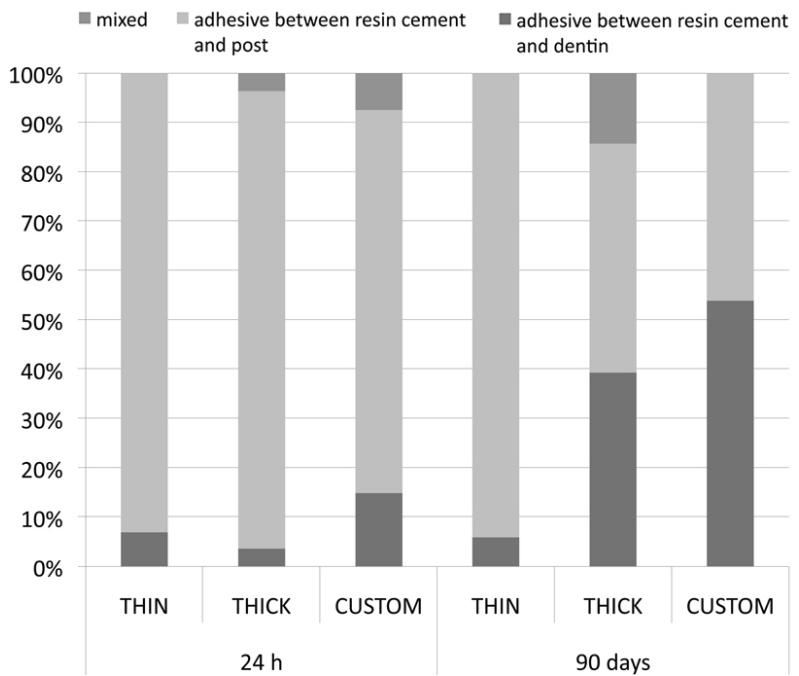

Figure 2. Failure mode distribution. considered that the posts fabricated with unidirectional glass fibers or machined in CAD-CAM are unique structures without additional interfaces, which could favor the stress distribution to the root. It is also important to note that there is still no consensus on how to treat properly the surface of customized posts with composite resin before cementation.

Also in relation to posts customized with composite resin, another aspect to be discussed is the difference in the interaction of the self-adhesive resin cement with the surface of the customized post (composite interface) compared with the prefabricated glass fiber posts. As the epoxy resin matrix of the glass fiber post is highly crosslinked (18), resin cements and composite resins cannot form strong chemical bonds with the post surface. Thus, in the case of prefabricated posts, failure is more likely to occur at the interface between post and cement. For the customized posts, a better bond strength may be obtained between resin cement and composite resin, and there may be a greater chance of failure between the glass fiber post and the composite resin used for customization. However, in this study, no failures were identified between fiber post and composite resin, indicating that this bond was effective. For all groups, the greatest number of failures occurred at the interfaces between resin cement and post, and between resin cement and dentin.

Regarding the surface treatment of the glass fiber post for the customization with composite resin, some studies provide little information about the subject, not reporting properly the materials and steps, and there is no standard protocol for this procedure. In this study, phosphoric acid was used to clean the post surface and a layer of simplified adhesive system was applied. Before the adhesive, a silane coupling agent could have been used, but silanization was not performed because there is no consensus that silane
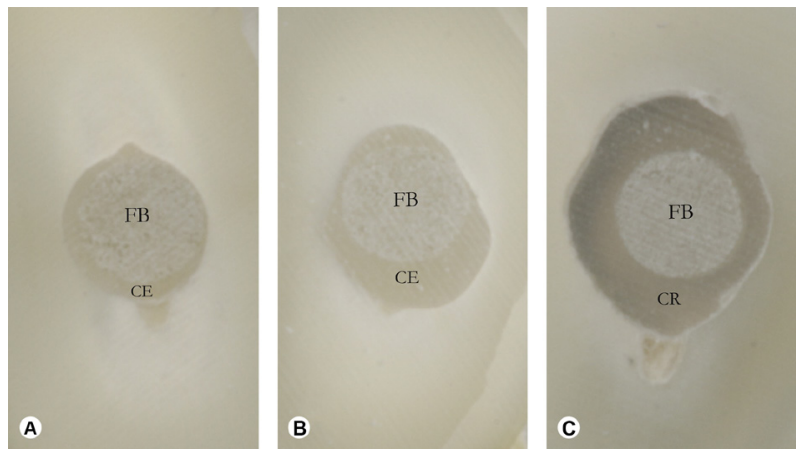

Figure 3. General view of coronal third slices for all groups: A: thin resin cement layer; B: thick resin cement layer; and C: customized post with a layer of translucent composite resin, well adapted to the prepared post space, with no visible resin cement layer. $\mathrm{FP}=$ fiber post; $\mathrm{CE}=$ resin cement; $\mathrm{CR}=$ composite resin. 
improves the bond between glass fiber posts and resinbased materials (19). The procedures for customization of the post in the present work were similar to those reported in the literature (17).

Debonding is still considered an important reason for failure of intra-radicular fiber posts. Considering that the adhesive cementation technique is the most suitable for the glass fiber post, some factors can negatively influence bond strength. Morphological differences between coronal dentin and root dentin should be considered. It is known that the root dentin may present a potentially lower hybridization and a suitable bonding agent should be used in these cases (20). Furthermore, the high C-factor in root canals (estimated at 200) may lead to a higher polymerization stress, reducing the bond strength (21). In this study, standard drills were used for standardization of the prepared post spaces in order to minimize the possible discrepancies.

Self-adhesive resin cements have been recommended for luting glass fiber posts and indirect restorations. Their indication is based on the fact that this technique is not so sensitive as for conventional resin cements, which require the use of adhesive systems. This could be important in confined spaces, such as root canals, where humidity control is limited, lack of direct visualization and control of adhesive procedures can render the bond strength less predictable in root dentin. Furthermore, these cements appear to exhibit high bond strength values and lower polymerization stress (22). Therefore, self-adhesive cements seem very promising for cementing glass fiber posts, reducing the clinical time and the possibility of errors in the dentin hybridization. In the present study, prior to cementation all posts were treated with phosphoric acid and silane application. This surface treatment may be required to improve the bond strength of glass fiber posts when self-adhesive resin cements are used. It is also reported that the application of an adhesive layer between fiber post and resin cement did not influence the bond strength when silane coupling agent was previously used (23).

The second hypothesis, that after aging in distilled water for 90 days there would be no decrease in bond strength values, regardless of the thickness of the cement layer, was also rejected because there was a significant difference for the group with thick cement layer, particularly in the apical third.

Studies with long storage periods in water or saliva and with thermal and/or mechanical cycling are important to monitor the bond strength values. In this study there was no statistically significant difference for the bond strength at $24 \mathrm{~h}$ for all root thirds. Thus, although the storage time in water was relatively short (90 days), it was sufficient to show a decrease in bond strength values, especially for the apical third, in the thick cement layer group $(-53,68 \%)$. In the thin cement layer group, although no statistical difference was observed, there was a decrease of 32.92\% on the bond strength after 90 days of storage. Perhaps the use of longer storage times and other forms of aging could reveal the difference.

Observing Figure 1, it is clear that the group thick cement layer group showed greater decrease in bond strength values $(-26.95 \%)$ than the groups with thin and custom cement layers $(-16.50 \%$ and $-6.80 \%$ respectively) after 90-day storage in distilled water. These data show that a thick cement layer may undergo more degradation and decrease in bond strength values over time. This may be related to greater water sorption by cement and hydrolytic degradation of the adhesive interface. However, it should be noted that there was no direct exposure of the cement in the slices, since the roots were stored prior to slicing. The conversion degree and polymerization of the cement could also affect this result. Self-adhesive cements have a lower conversion degree than the conventional cements, especially when chemical polymerization prevails in absence of light, for example in the middle and apical thirds. Aguiar et al. (24) showed that conventional (RelyX ARC) and selfadhesive cements (RelyX Unicem) differ in their conversion degrees after 5 and 20 min when evaluated in chemical and dual polymerization modes. For RelyX ARC conversion degree values were 69 to $72 \%$ (dual cure for $5 \mathrm{~min}$ and 20 $\mathrm{min}$, respectively), and 5 to $53 \%$ (chemical cure for $5 \mathrm{~min}$ and $20 \mathrm{~min}$, respectively). For RelyX Unicem, the conversion degree ranged from 51 to $54 \%$ (dual cure, 5 min and 20 $\mathrm{min}$, respectively), and 5 to 23\% (chemical cure, $5 \mathrm{~min}$ and $20 \mathrm{~min}$, respectively). This explanation seems to be more relevant, since the conversion degree of cement may not have been very high and because of the light attenuation in different areas of the root. It may be speculated that a resin cement with lower conversion degree and a thicker cement layer could produce worse bond strength results than with thinner cement layers. However, these hypotheses have to be tested and confirmed in further studies.

Lower values of bond strength in the apical third may be explained by several factors. The apical region presents additional difficulties with regard to the insertion and curing of adhesives and cements because of the light attenuation. This difficulty can be considered as one of the main reasons for a less effective bond in this third (25). It is also known that there is a significant reduction in the amount of transmitted light with increased depth and that the light intensity can achieve insufficient levels to ensure proper polymerization, especially in the apical third (26).

Prior to the push-out tests all cross sections were photographed to measure the thickness of the actual cement layer in each group and third and correlate it 
with the bond strength. However, this was not possible due the difficulties in the cement layer identification, particularly for the customized posts group. Because the post is quite fit to the post space, and the shades of the post, composite and resin cement were similar, there was great difficulty in determining the cement thickness, even at high magnification (Fig. 3).

The analysis of failure modes revealed that all failures occurred between cement and post, between cement and dentin, or were mixed. These results suggest that the bond strength values were representative and provided a reliable estimate in the tested conditions.

Finally, this study demonstrated the occurrence of a strong negative correlation between the thickness of the resin cement and the bond strength values, indicating that the greater the thickness of the cement, the lower the bond strength. According to the results of this study it must be emphasized that clinicians should seek the lowest possible thickness of resin cement when luting glass fiber posts. Furthermore, the customization of glass fiber posts with composite resin seems to be an interesting alternative when there is no good fit between the post and the prepared post space.

It may be concluded that there was an influence of the resin cement thickness in the bond strength of customized and prefabricated glass fiber posts, and customized post showed higher bond strength values. The storage in distilled water for 90 days affected negatively the bond strength values, especially in the apical third when thick cement layers were used.

\section{Resumo}

0 objetivo deste estudo foi avaliar a influência da espessura da linha de cimento na resistência de união de pinos de fibra de vidro após armazenamento em água destilada. Trinta dentes humanos hígidos unirradiculares tiveram os canais tratados endodonticamente. As raizes foram distribuidas em três grupos: THIN (linha de cimento fina): conduto preparado com broca 0,5 e cimentação de pino 0,5; THICK (linha de cimento espessa): conduto preparado com broca 1 e cimentação de pino 0,5; e CUSTOM (linha de cimento personalizada): conduto preparado com broca 1 e cimentação de pino personalizada (pino 0,5 personalizado com resina composta). Os pinos foram cimentados com cimento autoadesivo. Após armazenamento das raizes em água destilada a $37{ }^{\circ} \mathrm{C}$ por $24 \mathrm{~h}$ e 90 dias, o teste de cisalhamento por extrusão push-out foi realizado. Os resultados foram analisados estatisticamente por ANOVA a três fatores e teste de Tukey $(\alpha=0,05)$. A resistência de união foi significativamente maior para CUSTOM $(9,37 \mathrm{MPa})$, do que para THIN (7,85 MPa) e THICK (7,07 MPa), que foram semelhantes entre si. Considerando-se os terços radiculares, a resistência de união variou na sequência: apical $(7,13 \mathrm{MPa})<$ médio $(8,22 \mathrm{MPa})=$ coronal $(8,94$ $\mathrm{MPa}$ ). A resistência de união após $24 \mathrm{~h}$ de armazenamento em água foi significativamente maior $(8,80 \mathrm{MPa})$ do que para 90 dias $(7,40 \mathrm{MPa})$. Pode-se concluir que houve influência da espessura da linha de cimento na resistência de união de pinos de fibra de vidro, sendo que o uso de pinos personalizados apresentou maiores valores de resistência de união. 0 armazenamento em água por 90 dias afetou negativamente os valores de resistência de união, especialmente no terço apical, no grupo com linha de cimento mais espessa.

\section{References}

1. Gomez-Polo M, Llido B, Rivero A, Del Rio J, Celemin A. A 10-year retrospective study of the survival rate of teeth restored with metal prefabricated posts versus cast metal posts and cores. J Dent 2010;38:916-920.

2. Zicari F, Coutinho $E$, Scotti R, Van Meerbeek B, Naert I. Mechanical properties and micro-morphology of fiber posts. Dent Mater 2013;29:e45-e52.

3. Porciani PF, Coniglio I, Magni E, Grandini S. Fiber post fitting to canal anatomy: a review of the morphology and shape of root canal system. Int Dent SA 2008;10:52-58.

4. Coniglio I, Garcia-Godoy F, Magni E, Carvalho CA, Ferrari M. Resin cement thickness in oval-shaped canals: oval vs. circular fiber posts in combination with different tips/drills for post space preparation. Am J Dent 2009;22:290-294.

5. Grandini S, Goracci C, Monticelli F, Borracchini A, Ferrari M. SEM evaluation of the cement layer thickness after luting two different posts. J Adhes Dent 2005;7:235-240.

6. Silva NR, Aguiar GCR, Rodrigues MP, Bicalho AA, Soares PBF, Soares CJ. Effect of resin cement porosity on retention of glass-fiber posts to root dentin: an experimental and finite element analysis. Braz Dental J 2015;26:630-636.

7. D'Arcangelo $C$, Cinelli M, De Angelis F, D'Amario $M$. The effect of resin cement film thickness on the pullout strength of a fiber-reinforced post system. J Prosthet Dent 2007;98:193-198.

8. Costa RG, De Morais EC, Campos EA, Michel MD, Gonzaga CC, Correr $\mathrm{GM}$. Customized fiber glass posts. Fatigue and fracture resistance. Am J Dent 2012;25:35-38.

9. Liu P, Deng XL, Wang XZ. Use of a CAD/CAM-fabricated glass fiber post and core to restore fractured anterior teeth: A clinical report. J Prosthet Dent 2010;103:330-333.

10. Savi A, Manfredi M, Tamani M, Fazzi M, Pizzi S. Use of customized fiber posts for the aesthetic treatment of severely compromised teeth: a case report. Dent Traumatol 2008;24:671-675.

11. Egilmez F, Ergun G, Cekic-Nagas I, Vallittu PK, Lassila LV. Influence of cement thickness on the bond strength of tooth-colored posts to root dentin after thermal cycling. Acta Odontol Scand 2013;71:175-182.

12. Gomes GM, Rezende EC, Gomes OM, Gomes JC, Loguercio AD, Reis $A$. Influence of the resin cement thickness on bond strength and gap formation of fiber posts bonded to root dentin. J Adhes Dent 2014;16:71-78.

13. Ozcan E, Cetin AR, Tuncdemir AR, Ulker M. The effect of luting cement thicknesses on the push-out bond strength of the fiber posts. Acta Odontol Scand 2013;71:703-709.

14. Nova V, Karygianni L, Altenburger MJ, Wolkewitz M, Kielbassa AM, Wrbas KT. Pull-out bond strength of a fibre-reinforced composite post system luted with self-adhesive resin cements. J Dent 2013;41:10201026.

15. Perdigao J, Gomes G, Augusto V. The effect of dowel space on the bond strengths of fiber posts. J Prosthodont 2007;16:154-164.

16. Ferrari M, Cagidiaco MC, Goracci C, Vichi A, Mason PN, Radovic I, et al.. Long-term retrospective study of the clinical performance of fiber posts. Am J Dent 2007;20:287-291.

17. Aggarwal V, Singla M, Miglani S, Kohli S. Comparative evaluation of fracture resistance of structurally compromised canals restored with different dowel methods. J Prosthodont 2012;21:312-316.

18. Bell AM, Lassila LV, Kangasniemi I, Vallittu PK. Bonding of fibrereinforced composite post to root canal dentin. J Dent 2005;33:533539.

19. Tian $Y, M u Y$, Setzer $F C, L u H, Q u T, Y u$ O. Failure of fiber posts after cementation with different adhesives with or without silanization investigated by pullout tests and scanning electron microscopy. J Endod 2012;38:1279-1282.

20. De Goes MF, Giannini M, Foxton RM, Nikaido T, Tagami J. Microtensile bond strength between crown and root dentin and two adhesive systems. J Prosthet Dent 2007;97:223-228.

21. Bouillaguet S, Troesch S, Wataha JC, Krejci I, Meyer JM, Pashley DH. Microtensile bond strength between adhesive cements and root canal 
dentin. Dent Mater 2003:19:199-205.

22. Bergoli $C D$, Amaral M, Boaro LC, Braga RR, Valandro LF. Fiber post cementation strategies: effect of mechanical cycling on push-out bond strength and cement polymerization stress. J Adhes Dent 2012;14:471478.

23. Leme AA, Pinho AL, de Goncalves $L$, Correr-Sobrinho L, Sinhoreti MA. Effects of silane application on luting fiber posts using self-adhesive resin cement. J Adhes Dent 2013;15:269-274..

24. Aguiar TR, de Oliveira M, Arrais CA, Ambrosano GM, Rueggeberg

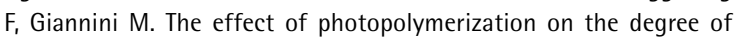
conversion, polymerization kinetic, biaxial flexure strength, and modulus of self-adhesive resin cements. J Prosthet Dent 2015:113:128134.

25. Foxton RM, Nakajima M, Tagami J, Miura H. Bonding of photo and dual-cure adhesives to root canal dentin. Oper Dent 2003;28:543-551.

26. Santos Alves Morgan LF, Peixoto RT, Castro Albuquerque R, Santos Correa MF, de Abreu Poletto LT, Pinotti MB. Light transmission through a translucent fiber post. J Endod 2008;34:299-302.

Received March 14, 2016 Accepted July 8, 2016 